\title{
An Exploration of the Application of Data integration in Enterprise Informationization Construction
}

\author{
Deming ZENG \\ Luzhou Vocational and Technical College, Luzhou Sichuan, China 646005
}

Keywords: Data integration, Informationization, Business to Business, Necessity.

\begin{abstract}
At present, enterprises have been developing more and more quickly in China. In order to strengthen the systems of enterprise management, manufacturing execution, equipment and so on in each link of management, many enterprises have started to use data integration to construct an Informationization management system. Based on the needs of the development of enterprises, this paper analyzes the pattern formation of data integration and its advantages and explores its role in enterprise informationization construction.
\end{abstract}

\section{Introduction}

In the times of informationization, informationization development is a necessary stage for every enterprise to go through in metamorphosis. In the process of enterprises' development, it is easy to form "information island" due to failure of communication or trade restrictions, which troubles either decision-making or management for them. Latitudinally,enterprises need to receive the latest industry news for development; longitudinally, they need to summarize experience of historical development; on the whole, they need to integrate information from each subsumed department. In all, informationization is necessary, so is data integration for enterprises' development in terms of the three above-mentioned aspects.

\section{Data Integration}

The so called data integration is divided into three layers in the light of its structure, i.e., data-capture layer, data management layer and data service layer, as is shown in Fig. 1 below.

The data-capture layer is responsible for capturing and updating available data and then registering them as data source. The data abstraction model, namely, data-capture layer, first monitors and analyzes data from data sources in storage. As an enterprise embodies a big database, the basis of model construction relies on data collection. Therefore, it is necessary for the data extraction model to detect changes in data for adding in data at all times.

The data management layer is responsible for data integration, i.e., management and maintenance on the basis of data. As the data is in a scattered state after being collected, only when they are integrated and classified will they be available for backup use.

The data service layer provides useful information for decision makers pointedly and selectively. However, decision making calls for precise and accurate data. Hence, the provided information is supposed to having been analyzed in one way or another to the necessity of decision making.

All the three layers are constituents of EAI (Enterprise Application Integration). They seem to perform different functions, but constitute an inter-related and indivisible whole. They are all described in XML because the language is both easy to use and has good performance. Data 
extraction, transfer and loading are all components of the establishment and maintenance of database, for which several key techniques are adopted including data extraction model design.

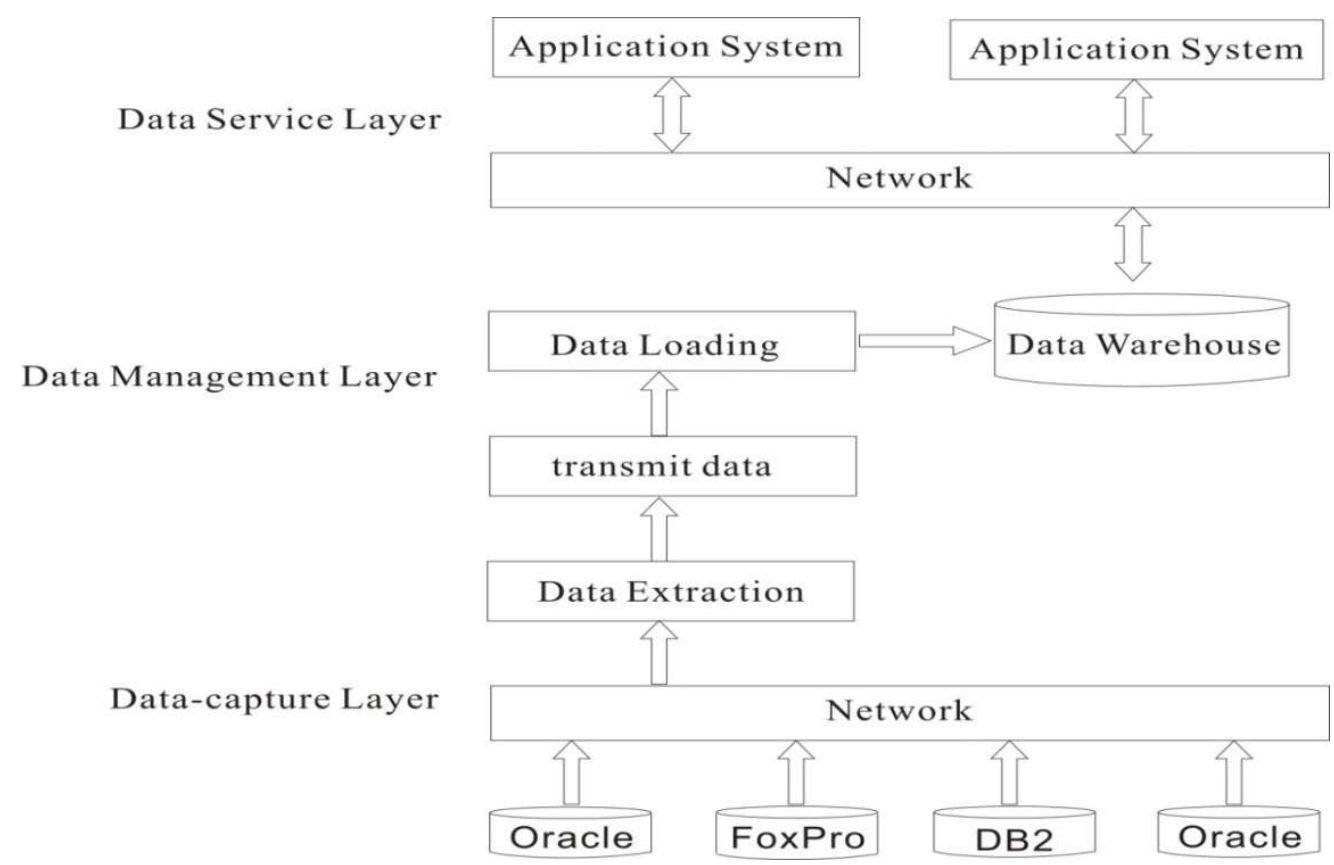

Figure 1 Layer Diagram of Data Integration System

The data load design, for example, is one of the core technologies employed for data integration. At present, inverse transformation of data is carried out with the help of XML. That is, XML data is transformed into target data; it is also a process of loading data into database. In the process of data loading, target increment table is a key point as well as the source of data to be loaded.The names for the target increment table may includean extracted table name with the suffix "-dest"or flag, updatetime, etc. addingall of the fields of the corresponding target. In general, constructing data loading first requires connecting the database to the target database and then the data in the target increment table load to the target database.That is the process of data loading design, wherein the loading method employed for the target increment table as the data source can import data of similar structure without switching in the context of the database.

This greatly improves the performance of data loading.

\section{Necessity of Data Integration}

Nowadays, informationization is becoming more and more important. In addition to capital and technology, information has become an important factor for the development enterprises. Therefore, database technology has become the hot spot of research and received as much attention as in the research both at home and abroad. But most of the concern has been focused on technology and integration framework, which has changed related methods of data integration and is of great help for enterprises to improve flexibility and collaboration capabilities.

It is widely acknowledged that database has good real-time performance. But it has certain requirements for network and devices and its cost is high. If the transformation and transmission is processed through data replication, even though the data could be delayed, the access will be faster and cost will be lower. Therefore, it can be concluded that although data integration has faults, the methods for its implementation are simple. Besides, it is flexible in s data processing andhas good maintainability; thus feasible. In the meantime, it is also an "informationization revolution" necessary for enterprises to carry out to stand in the tide of information in the information age. 


\section{Application of Data Integration}

The application of data integration in enterprises can be summarized as five stratified systems including device control system as shows Fig 2 in the following.

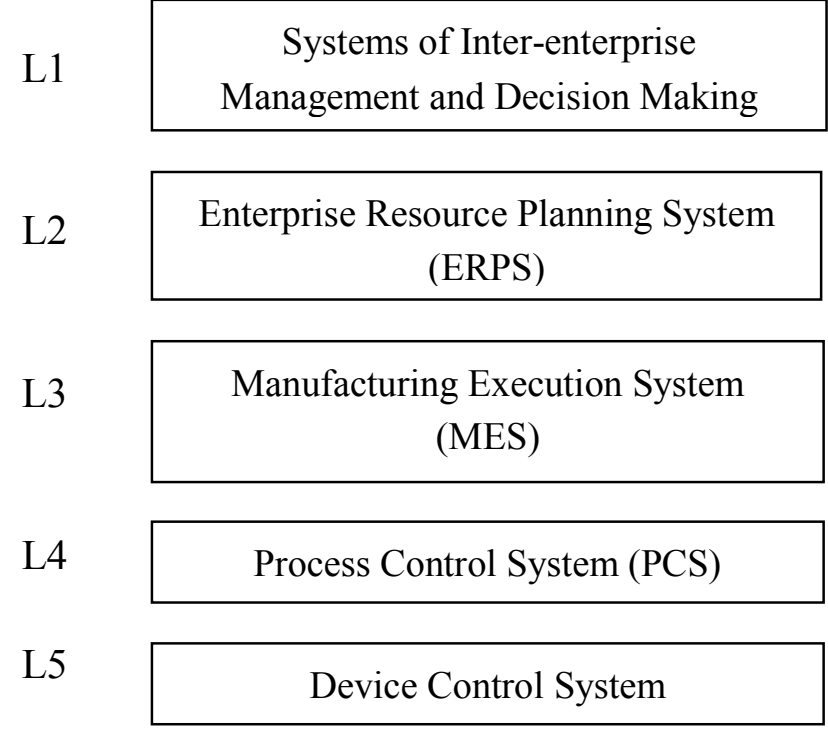

Figure 2 System of Data Integration Construction

In the above system, from L1 to L3 are in strict interdependencies while L4 and L5 are less strict. Among them, the integration of from L1 to L4 is commonly seen in A2A (or ATA, namely Application to Application) integration while that of L4 and L5 is common in B2B (or BTB, namely Business to Business) integration. Here, the discussion takes B2B for an example, concerning the relationship between data integration and enterprise development.

B2B is a kind of marketing relationship between enterprises, which realizes tight and close combination of the Intranet and customers through B2B websites and provides customers with more quality services upon the advantages of rapid network response; thereby giving impetus to the development of enterprises in the aspect of the business in order to speed up the development of enterprises.

B2B integration is a loosely coupled dynamic integration. Because resolve all kinds of service composition can be dynamically discovered and resolved in the operation of L4 and L5, the two layers are suitable for B2B integration. The main frameworks of B2B include UN/CE-FACT, ebXML by OASIS, eCoby by CommerceNet, Web Services architecture jointely launched by BM, Microsoft and other companies, and PIP specifications by Rosettant. Among them, the Web Services architecture can be divided into multiple services, but the integration of L4 and L5 has the most outstanding performance. It can be said that the integrated system B2B describes by XML can not only integrate the information of the enterprises themselves but also combine the information between businesses and their customers for the best decision making.

ERPS deals with the sales forecast out of the analysis orders by the CRM system and reaches the purchase and production orders. Then the SCM system performs tracking and monitoring and sending orders to MES, which will do resources and production scheduling and give orders to workers and device control system. After receiving feedback information MES extracts and processes it and have it fed to the ERP system. In this work model, a full and complete connection runs through from the customer to the supplier and transactions are carried out in integration.

Therefore, it can be generalized that after completing data integration enterprises exemplified by B2B can: (1) use the CRM system to interact with customers; (2) accurately grasp the customers' 
demand and provide them with satisfactory service; (3) save costs by using the SCM system; (4) reduce the stock of goods and form supply chains; and (5) connect business and management through the ERP system, thus forming a networking process and establishing a trading hub. Therefore, data integration can pass customers' requirements and orders through network in the form of zero wait to the whole supply chain and make trading and supply almost be generated at the same time. This is the advantage data integration brings enterprises.

\section{Summary}

Data integration is the key to informationization, so it occupies an important position in development of enterprises. However, through the above analysis it should be borne on mind that it has both advantages and defects and that it requires continuous improvement as to form a better information system. At the same time, enterprises' informationization constructionis also a process in need of sustainable development as well a development process that has only beginningsbutno endings. For this reason, it is necessary to combine the two to bring about synchronous development for the final formation of an informationization era of enterprises' development.

\section{Author in brief}

Deming ZENG, born in Matan, Sichuan Province in 1970, male, associate professor, Sichuan Provincial Government Procurement Expert, academic pacemaker, whose research fields include application of enterprise informationization integration, information security technology, computer science and technology, etc.

\section{References}

[1] C. Y. Ma, Y. X. Yu and H. D. Chen, Application of data integration in enterprise information construction, Computer and Digital Engineering. 7, 297 (2014)1238-1241.

[2] J. K. Hua, W. J. Deng, The application of data integration technology in EAI, Computer Applications and Software. 12, 23 (2011)127-128.

[3] Y. K. Li, X. F. Meng and X. Y. Zhang, Research on data space, Journal of Software. 8, 19 (2008)2018-2031.

[4] H. T. Feng, J. Yang, Research on the application of system integration technology in the construction of informationization of enterprises, Information System Engineering. 7, (2011)2013-2015.

[5] Y. Xie, An exploration of data integration technology in enterprises' informationization construction, Telecom World.9 (2014) 301-303.

[6] J. Zhao, The application of computer technology in informationization construction of enterprises. Computer CD Software and Applications. 21 (2013)113-115.

[7] H. Zhou, An attempted analysis of the direction and countermeasures of informationization construction of enterprises, Scientific Consult(Policy and management). 4 (2009)202-204.

[8] X. L. Wang, Using computer technology to strengthen modern enterprise management, Liaoning Economy. 3 (2009)135-137. 